\title{
Thermodynamics of the system Fe-Si-O under high pressure and temperature and its implications for Earth's core
}

\author{
Tetsuya Komabayashi ${ }^{1}$ (D)
}

Received: 11 March 2020 / Accepted: 25 June 2020 / Published online: 3 July 2020

(c) The Author(s) 2020

\begin{abstract}
The thermodynamics of the system $\mathrm{Fe}-\mathrm{Si}-\mathrm{O}$ under high pressure $(P)$ and temperature $(T)$ was examined, starting with modelling the phase transition between a face-centred cubic (fcc) and hexagonal close-packed (hcp) structure in Fe-Si alloy which was previously examined by experiment under high $P-T$ conditions. The mixing properties of $\mathrm{Fe}$ and $\mathrm{Si}$ for the iron phases were found to be approximated by ideal mixing under high $P$ and $T$ conditions. The entropy changes upon melting of the end-members of the system are fairly large, and therefore the melting temperature of the Si-bearing fcc or hcp phases needs to be insensitive to the Si content, to account for the reported close compositions of coexisting liquid and solid $(<1$ wt $\% \mathrm{Si}$ at $P>50 \mathrm{GPa}$ ). The solidus and liquidus temperatures of Fe-Si iron alloy would therefore, not significantly be changed by the presence of $\mathrm{Si}$ at the inner core-outer core boundary, which enables us to evaluate the melting curve of Fe-Si fcc and hcp phases. From thus-constrained melting curve, I assessed a thermal equation of state of Si-bearing iron liquid. I then estimated a seismologically consistent outer core composition as a function of $\mathrm{Si}$ and $\mathrm{O}$ contents using the EoS for liquids constructed in this study and the literature. The best-fit composition is $\mathrm{Fe}-5.8(0.6) \mathrm{wt} \% \mathrm{Si}-0.8(0.6) \mathrm{wt} \% \mathrm{O}$, which however does not precipitate a solid iron phase that is consistent with the inner core density. Therefore, Earth's core cannot be fully represented by the system $\mathrm{Fe}-\mathrm{Si}-\mathrm{O}$ and it should include another light element.
\end{abstract}

Keywords Earth's core $\cdot$ High-pressure $\cdot$ Thermodynamics $\cdot \mathrm{Fe}-\mathrm{Si}$ alloy $\cdot \mathrm{Fe}-\mathrm{Si}-\mathrm{O}$ alloy $\cdot$ Equation of state

\section{Introduction}

Silicon and oxygen are considered major impurities present in Earth's iron-nickel core as a consequence of metal-silicate partitioning during core formation (Wade and Wood 2005; Rubie et al. 2011; Siebert et al. 2013). However, suggested concentrations of $\mathrm{Si}$ and $\mathrm{O}$ from element partitioning in the magma ocean vary among studies: $5-7 \mathrm{wt} \% \mathrm{Si}+0 \mathrm{wt} \% \mathrm{O}$ (Wade and Wood 2005), $8 \mathrm{wt} \% \mathrm{Si}+0.5 \mathrm{wt} \% \mathrm{O}$ (Rubie et al. 2011), and 1.5-2.2 wt\% Si + 4.5-5.5 wt\% O (Siebert et al. 2013). The validity of a hypothetical Si- and O-bearing iron core can be tested by comparing its predicted physical

Electronic supplementary material The online version of this article (https://doi.org/10.1007/s00269-020-01102-w) contains supplementary material, which is available to authorized users.

Tetsuya Komabayashi

tetsuya.komabayashi@ed.ac.uk

1 School of GeoSciences and Centre for Science at Extreme Conditions, University of Edinburgh, Grant Institute, King's Buildings, James Hutton Road, Edinburgh EH9 3FE, UK properties with seismologically constrained parameters which include the seismic $P$-wave velocity (Vp) and density. For a liquid core, the $\mathrm{Vp}$ and density can be calculated from a thermodynamic potential such as the Gibbs free energy as a function of pressure $(P)$, temperature $(T)$, and composition (e.g., Komabayashi 2014).

While thermodynamic models including mixing property of liquids were established for the system $\mathrm{Fe}-\mathrm{FeO}$ under core $P-T$ conditions (Frost et al. 2010; Komabayashi 2014), a self-consistent thermodynamic model for the system $\mathrm{Fe}-(\mathrm{Fe}) \mathrm{Si}$ which can be applicable to Earth's core has yet to be constructed although the system has extensively been studied by both experiment and first-principles calculation (Alfe et al. 2002; Dobson et al. 2002; Lin et al. 2002; Kuwayama and Hirose 2004; Tateno et al. 2015; Ozawa et al. 2016; Komabayashi et al. 2019). A thermodynamic model for the system $\mathrm{Fe}-\mathrm{Si}$ needs to address mixing property of $\mathrm{Fe}$ and $\mathrm{Si}$ in iron phases, since these phases form solutions and their nonideality affects the $P-T$ locations of chemical reactions involving them. The thermodynamic model established at 1 bar in metallurgy indicates that the body-centred 
cubic (bcc), face-centred cubic (fcc), and liquid phases show strong negative nonideality which stabilizes them more than what expected from ideal mixing (e.g., Kanibolotsky et al. 2003; Ohnuma et al. 2012). Although Huang et al. (2019) reported that the mixing of $\mathrm{Fe}, \mathrm{Si}$, and $\mathrm{O}$ in liquids under core pressures would be ideal from the first-principles calculations, the evolution of the mixing properties with increasing pressure and temperature needs to be evaluated from experimental data.

Another important part of thermodynamic modelling of the system $\mathrm{Fe}-\mathrm{Si}$ is inclusion of melting relations. The width of the melting loops of iron phases was studied by both experiment and theory because it is the key to understanding the Si partitioning between the solid inner core and liquid outer core when the inner core crystallises (Kuwayama and Hirose 2004; Ozawa et al. 2016; Alfe et al. 2002). At $1 \mathrm{bar}$ the width of the melting phase loop for the bcc phase is as narrow as $2 \mathrm{wt} \% \mathrm{Si}$ for $\mathrm{Fe}-5 \mathrm{wt} \% \mathrm{Si}$ (Kubaschewski 1993). Kuwayama and Hirose (2004) from high-pressure experiments in a multianvil apparatus suggested that the width of the melting loop for the fcc phase would be less than $2 \mathrm{wt} \% \mathrm{Si}$ at $21 \mathrm{GPa}$. Recently Ozawa et al. (2016) demonstrated from a DAC experiment that the fcc melting loop was as narrow as less than $1 \mathrm{wt} \% \mathrm{Si}$ at $58 \mathrm{GPa}$. Alfe et al. (2002) reported by first-principles calculation that silicon is almost equally partitioned between hexagonal close-packed (hcp) iron and liquid at $370 \mathrm{GPa}$. As such the width of melting loop of the iron phases seems to become narrower with increasing pressure from 1 bar to over 3 Mbar. However, those studies at pressures greater than $21 \mathrm{GPa}$ only determined the solid-liquid partitioning of silicon and the melting/crystallising point for $\mathrm{Fe}-\mathrm{Si}$ alloy was not determined (Ozawa et al. 2016; Alfe et al. 2002). The crystallising (i.e., liquidus) temperature of a Si-bearing iron system is important for constraining the temperature at the inner core-outer core boundary (ICB, at $330 \mathrm{GPa}$ ).

In this study, the mixing properties of Si-bearing iron phases are first examined by thermodynamic calculation of a phase transition loop. Komabayashi et al. (2019) constrained the width of the transition between fcc and hcp structures in $\mathrm{Fe}-4 \mathrm{wt} \% \mathrm{Si}$ to $71 \mathrm{GPa}$ and $2000 \mathrm{~K}$ in an internally resistiveheated diamond anvil cell (DAC) which enabled very precise measurements (Fig. 1). Then I extend the thermodynamic modelling to higher temperature to calculate the melting point under high pressure. By reproducing the reported Si partitioning data, I place constraints on the crystallising points of Si-bearing iron liquids to the inner core pressures. From the constrained melting temperatures over a wide pressure range, I evaluate a thermal equation of state (EoS) of an Fe-Si liquid. Then, combining Komabayashi (2014)'s model for the system $\mathrm{Fe}-\mathrm{FeO}$ with the results of this study, I address the nature of Fe-rich liquids in the system $\mathrm{Fe}-\mathrm{Si}-\mathrm{O}$; I calculate the density and $\mathrm{Vp}$ of liquids in

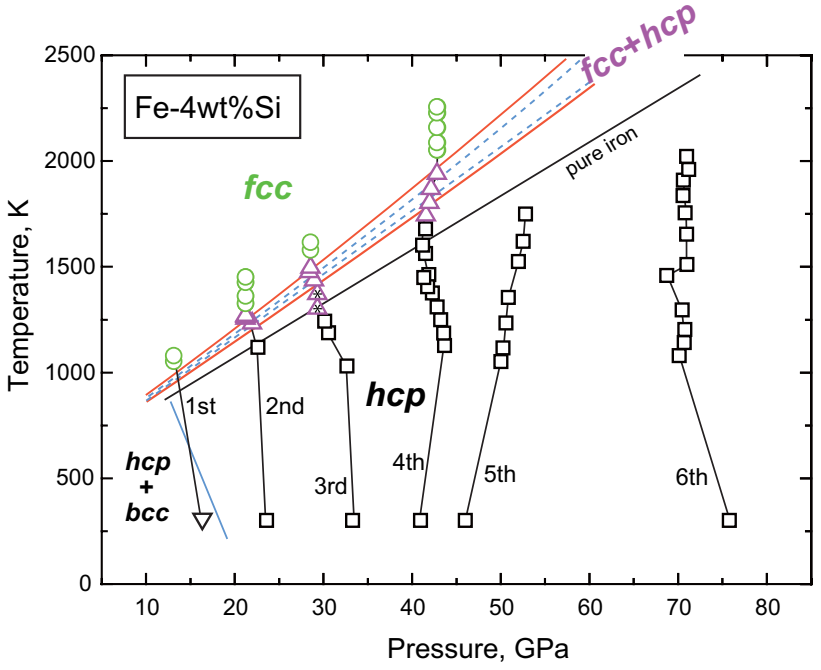

Fig. 1 Calculated fcc-hcp transition boundaries for Fe-4 wt\%Si with the ideal mixing model (red line) and nonideal mixing model (blue dashed line). Experimental results with in situ X-ray diffraction in an internally resistive-heated DAC are also plotted: inversed triangle, hcp + bcc; square, hcp; normal triangle, fcc + hcp; circle, fcc (Komabayashi et al. 2019). The black line is an experimentally constrained fcc-hcp transition boundary in pure iron (Komabayashi et al. 2009). The typical experimental uncertainty in temperature is $50 \mathrm{~K}$ while the data with asterisk have larger uncertainty of about $100 \mathrm{~K}$

the ternary system over the outer core pressure range and discuss the likely amounts of Si and O in Earth's outer core. I then calculate the density of the solid iron phase precipitating from the determined outer core composition. From these calculations, I finally discuss whether or not the system $\mathrm{Fe}-\mathrm{Si}-\mathrm{O}$ can represent Earth's core.

\section{Method}

To develop thermodynamic models for the fcc-hcp transitions and melting curve in the system $\mathrm{Fe}-\mathrm{Si}$, I followed the approach in metallurgy to modelling the Gibbs free energy (chemical potential) curves of $\mathrm{Fe}$ phases (e.g., hcp) as a function of the Si content; they were modelled between pure $\mathrm{Fe}$ and pure $\mathrm{Si}$ with the same structures. The thermodynamic properties of hypothetical fcc and hep Si at 1 bar were reported by the metallurgy literature (e.g., Dinsdale 1991) and their mixing properties were also available (e.g., Ohnuma et al. 2012). In the system $\mathrm{Fe}-\mathrm{Si}$, intermediate phases such as FeSi are stable depending on the $P-T$ condition, but those phases do not form a solid solution with the Fe phase as they have different structures. Instead, one can model the chemical potential curve of the Fe solid solution between Fe and hypothetical Si with the hcp 
structure; this does not violate the laws of thermodynamics as the chemical potentials of the (sub)system Fe-FeSi are properly buffered by $\mathrm{Fe}$ and $\mathrm{FeSi}$ phases when they have a common tangent in the potential-composition diagram. This is the most reasonable and practical approach as this provides the largest applicable range to the solid solution. For instance, when different intermediate phases become stable at different $P-T$ conditions, one would have to keep redefining their new end-members if one has to model the system with those intermediate phases, which is not sensible at all as this will likely introduce inconsistent behaviour of the system on a phase change. Indeed, the approach taken in this study was also adopted in Mineral Physics as well (Fei and Brosh 2014; Saxena and Eriksson 2015).

A phase transition in a binary system at constant pressure can be modelled with simultaneous equations (e.g., Cemič 2005):

$$
\begin{aligned}
& \ln \left(\frac{a_{\mathrm{Fe}}^{\mathrm{fcc}}}{a_{\mathrm{Fe}}^{\mathrm{hcp}}}\right)=\frac{\Delta S_{\mathrm{Fe}}^{\mathrm{fcc}-\mathrm{hcp}}}{R}\left(1-\frac{T_{\mathrm{Fe}}^{\mathrm{fcc}-\mathrm{hcp}}}{T}\right) \\
& \ln \left(\frac{a_{\mathrm{Si}}^{\mathrm{fcc}}}{a_{\mathrm{Si}}^{\mathrm{hcp}}}\right)=\frac{\Delta S_{\mathrm{Si}}^{\mathrm{fcc}-\mathrm{hcp}}}{R}\left(1-\frac{T_{\mathrm{Si}}^{\mathrm{fcc}-\mathrm{hcp}}}{T}\right)
\end{aligned}
$$

where $R$ is the gas constant, and for instance, $a_{\mathrm{Fe}}^{\mathrm{fcc}}$ is the activity of $\mathrm{Fe}$ in the fcc phase, $\Delta S_{\mathrm{Fe}}^{\mathrm{fcc}-\mathrm{hcp}}$ is the entropy change upon the fcc-hcp transition for the Fe end-member, $T_{\mathrm{Fe}}^{\mathrm{fcc}-\mathrm{hcp}}$ is the transition temperature for the Fe endmember. The parameters for the $\mathrm{Fe}$ end-member were from an experimental determination of the fcc-hcp transition (Komabayashi et al. 2009) and a thermodynamic model (Komabayashi 2014). For the hypothetical Si end-member phases with the fcc and hcp structures, the database for 1 bar by Dinsdale (1991) was adopted. The value for $\Delta S_{\mathrm{Si}}^{\mathrm{fcc}-\mathrm{h} p}$ was assumed to be constant over the $P-T$ range studied here, which is a reasonable assumption for a solid-solid phase transition when the detailed thermodynamic data is not available.

The activity is described as:

$a=\gamma X$

where $\gamma$ is the activity coefficient and $X$ is the mole fraction of a component. I employed ideal mixing $(\gamma=1)$ and nonideal mixing for the fcc-hcp transitions. The Gibbs free energy of a nonideal solution $\left(G_{\mathrm{m}}\right)$ is expressed as (Guggenheim 1937; Redlich and Kister 1948; Ohnuma et al. 2012):

$$
\begin{aligned}
G_{\mathrm{m}}= & { }^{\circ} G_{\mathrm{Fe}} * X_{\mathrm{Fe}}+{ }^{\circ} G_{\mathrm{Si}} * X_{\mathrm{Si}} \\
& +\mathrm{RT}\left(X_{\mathrm{Fe}} \ln X_{\mathrm{Fe}}+X_{\mathrm{Si}} \ln X_{\mathrm{Si}}\right)+X_{\mathrm{Fe}} X_{\mathrm{Si}} * L_{\mathrm{Fe}, \mathrm{Si}}
\end{aligned}
$$

where ${ }^{\circ} G_{\mathrm{Fe}}$ and ${ }^{\circ} G_{\mathrm{Si}}$ are the Gibbs energies of the end-member pure phases, $L_{\mathrm{Fe}, \mathrm{Si}}$ represents the interaction parameters which is based on a power series representation:

$L_{\mathrm{Fe}, \mathrm{Si}}=\sum_{n}\left(X_{\mathrm{Fe}}-X_{\mathrm{Si}}\right)^{n} *{ }^{n} L_{\mathrm{Fe}, \mathrm{Si}}$

Equations (4) and (5) yield,

$$
\begin{aligned}
\mathrm{RT} \ln \gamma_{\mathrm{Fe}}= & X_{\mathrm{Si}}^{2}\left[{ }^{0} L_{\mathrm{Fe}, \mathrm{Si}}+{ }^{1} L_{\mathrm{Fe}, \mathrm{Si}}\left(3-4 X_{\mathrm{Si}}\right)\right. \\
& \left.+{ }^{2} L_{\mathrm{Fe}, \mathrm{Si}}\left(1-2 X_{\mathrm{Si}}\right)\left(5-6 X_{\mathrm{Si}}\right)\right\rfloor
\end{aligned}
$$

$$
\begin{aligned}
\mathrm{RT} \ln \gamma_{\mathrm{Si}}= & \left(1-X_{\mathrm{Si}}\right)^{2}\left\lfloor{ }^{0} L_{\mathrm{Fe}, \mathrm{Si}}+{ }^{1} L_{\mathrm{Fe}, \mathrm{Si}}\left(1-4 X_{\mathrm{Si}}\right)\right. \\
& \left.+{ }^{2} L_{\mathrm{Fe}, \mathrm{Si}}\left(2 X_{\mathrm{Si}}-1\right)\left(6 X_{\mathrm{Si}}-1\right)\right\rfloor
\end{aligned}
$$

See Cemič (2005, pp. 194-195) for the details of the derivation of the above equations. In the present calculations, Eqs. (6) and (7) were used to obtain $\gamma$ and (4) and (5) were not directly used. We adopted an activity model for the fcc phase at 1 bar in the system Fe-Si (Ohnuma et al. 2012). As there is no mixing model for the hcp phase available, I assumed the same activity model for the fcc and hcp phases as they have similar stacking structures.

\section{Results}

\section{Fcc-hcp transition in Fe-4wt\%Si}

Figure 1 shows calculated phase boundaries for the fcc-hcp transitions in $\mathrm{Fe}-4 \mathrm{wt} \% \mathrm{Si}$. With all the parameters for $\mathrm{Fe}$ well-constrained (Komabayashi 2014), the calculated $\mathrm{d} P /$ $\mathrm{d} T$ slope of the fcc-hcp transition depends on (i) $T_{\mathrm{Si}}^{\mathrm{fcc}-\mathrm{hcp}}$ and its pressure dependence and (ii) mixing properties of the phases. For (i), the value at 1 bar (Dinsdale 1991) was adopted and its pressure dependence was assessed in this study so that the calculation reproduces the experimental data (Komabayashi et al. 2019) (Fig. 1). For (ii), I tested two mixing models for the phases: (a) nonideal mixing and (b) ideal mixing. For (a), Ohnuma et al. (2012) proposed a sub-regular solution model for the fcc phase at 1 bar. Their mixing model was used to calculate the fcc-hcp transition boundaries assuming no pressure and temperature dependence on the interaction parameters. As mentioned above, the same interaction parameters were employed for the fcc and hcp phases. The used parameters are listed in Table 1. Note that Asanuma et al. (2008) earlier reported fcc-hcp transition boundaries in Fe-3.4 wt\% Si using a laser-heated DAC, and found a much wider fcc + hcp coexistence region than in Komabayashi et al. (2019) under the same $P-T$ conditions. In addition, the fcc-in boundary in Asanuma et al. (2008) was located at temperatures lower than the pure Fe boundary. 
Table 1 Thermodynamic parameters used in the calculations

\begin{tabular}{|c|c|c|c|c|}
\hline Pressure, GPa & 20 & 40 & 60 & \\
\hline \multicolumn{5}{|c|}{ fcc-hcp transition (ideal and nonideal mixing) } \\
\hline$T_{\mathrm{Fe}}^{\mathrm{fcc}-\mathrm{hcp}}, \mathrm{K}$ & 1080 & 1570 & 2090 & Komabayashi et al. (2009) \\
\hline$T_{\mathrm{Si}}^{\mathrm{fcc}-\mathrm{hcp}}, \mathrm{K}$ & & $1800+225 * \mathrm{P}($ in GPa $)$ & & Dinsdale (1991); this study \\
\hline$\Delta S_{\mathrm{Fe}}^{\mathrm{fcc}-\mathrm{hcp}}, \mathrm{J} \mathrm{K}^{-1} \mathrm{~mol}^{-1}$ & 4.27 & 3.53 & 3.00 & Komabayashi (2014) \\
\hline$\Delta S_{\mathrm{Si}}^{\mathrm{fcc}-\mathrm{hcp}}, \mathrm{J} \mathrm{K}^{-1} \mathrm{~mol}^{-1}$ & 1.00 & 1.00 & 1.00 & Dinsdale (1991) \\
\hline Mixing parameters & ${ }^{0} L_{\mathrm{Fe}, \mathrm{Si}}$ & ${ }^{1} L_{\mathrm{Fe}, \mathrm{Si}}$ & ${ }^{2} L_{\mathrm{Fe}, \mathrm{Si}}$ & \\
\hline fcc & $-167,164.9+42.9734 * \mathrm{~T}($ in $\mathrm{K})$ & $-44,950.4$ & $19,706.6$ & Ohnuma et al. (2012) \\
\hline hcp & $-167,164.9+42.9734 * \mathrm{~T}($ in K) & $-44,950.4$ & $19,706.6$ & $\begin{array}{l}\text { Assumed to be the same as } \\
\text { for the fcc phase }\end{array}$ \\
\hline Pressure, GPa & 60 & 330 & & \\
\hline \multicolumn{5}{|l|}{ Melting (ideal mixing) } \\
\hline$T_{\mathrm{Fe}}^{\text {melting }}, \mathrm{K}$ & 2910 & 6380 & & Komabayashi (2014) \\
\hline$T_{\mathrm{Si}}^{\text {melting }}, \mathrm{K}$ & 2600 & 6380 & & This study \\
\hline$\Delta S_{\mathrm{Fe}}^{\text {melting }}, \mathrm{J} \mathrm{K}^{-1} \mathrm{~mol}^{-1}$ & 7.87 & 7.17 & & Komabayashi (2014) \\
\hline$\Delta S_{\mathrm{Si}}^{\text {melting }}, \mathrm{J} \mathrm{K}^{-1} \mathrm{~mol}^{-1}$ & 8.30 & 10.46 & & Dinsdale (1991) \\
\hline
\end{tabular}

As was extensively discussed in Komabayashi et al. (2019), the appearance of fcc peaks in X-ray diffraction patterns was not clearly recognized in Asanuma et al. (2008). The results of Komabayashi et al. (2019) on the $P-T$ location of the fcc-hcp boundaries are consistent with more recent works by Fischer et al. (2013) and Tateno et al. (2015).

The calculated transition boundaries with the nonideal mixing model yielded a slightly narrower phase loop than with the ideal mixing model under high pressures (Fig. 1). Figure 2 shows misfits of calculated transition temperatures to experimental data. The experimental data points in the 1 st run are at much (a few $10 \mathrm{~K}$ ) higher temperatures than the equilibrium reactions lines, namely they lie well within the fcc stability field. In the experiment by Komabayashi et al. (2019), the sample was directly heated from $300 \mathrm{~K}$ to the fcc stability field at 1050-1060 K, and therefore the equilibrium point was not bracketed. On the 3rd run, the misfits of the fcc-in data point are as large as 160-180 K because of larger experimental uncertainties in temperature (Komabayashi et al. 2019) (Fig. 2). Those data points were not considered when I fitted the thermodynamic parameters simply due to the larger experimental uncertainty. Except for those data points in the 1st and 3rd runs, the transition temperatures were reasonably reproduced by both ideal and nonideal mixing models (Fig. 2). Note that the experimental data in Figs. 1 and 2 are of the greatest precision in temperature $(50 \mathrm{~K})$ for a diamond anvil cell experiment at temperatures greater than $1400 \mathrm{~K}$ (i.e., temperatures are measured with the spectroscopic method) as it was conducted in the internally-resistive heating system.

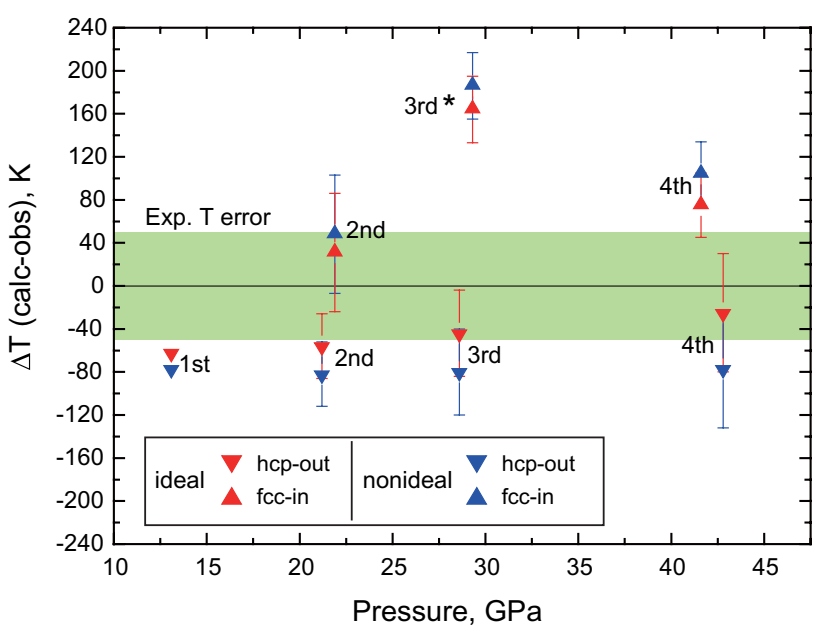

Fig. 2 Misfits of calculated transition temperatures to experimental data on the fcc-hcp transition boundaries (Komabayashi et al. 2019). Typical temperature uncertainties $(50 \mathrm{~K})$ are shown as the green band. The error bar attached to each data point denotes the range of bracketing equilibrium point. In the 1 st run, the fcc-in reaction was not constrained and the hcp-out reaction might have been overshot in the experiment (Komabayashi et al. 2019). For the fcc-in data in the 3 rd run (asterisk) were with a larger temperature uncertainty and not considered when evaluating the thermodynamics of the boundaries in this study

The above analysis demonstrates that the ideal mixing model can be applied to the hcp and fcc phases under high pressures as well as the nonideal model. As the nonideal mixing model was established at 1 bar and can be used up to $3500 \mathrm{~K}$ (Ohnuma et al. 2012), I will use the ideal 
mixing model for the phases in the following calculations under core $P-T$ conditions.

\section{Melting of Si-bearing fcc and hcp Fe phases under high pressure}

The melting temperature of a Si-bearing iron phase (fcc or hcp) was not measured at pressures greater than $21 \mathrm{GPa}$ (Kuwayama and Hirose 2004), although highpressure experiments observed melting of the B2 phase or eutectic of $\mathrm{Fe}+\mathrm{B} 2$ in the system $\mathrm{Fe}-(\mathrm{Ni})-\mathrm{Si}$ at the Si-rich side ( $\mathrm{Si}>10 \mathrm{wt} \%$ ) (Asanuma et al. 2010; Morard et al. 2011; Fischer et al. 2013; Lord et al. 2014). Here I estimated the melting temperatures of Si-bearing fcc and hcp phases through calculations of the melting phase loops. An experimental study reported narrow melting loops, $<1 \mathrm{wt} \% \mathrm{Si}$, at about $60 \mathrm{GPa}$ (Ozawa et al. 2016) and a theoretical study (Alfe et al. 2002) predicted a much narrower loop in that $\mathrm{Si}$ is almost equally partitioned between solid and liquid at $370 \mathrm{GPa}$. I calculated the melting loops using Eqs. (1) and (2) adopting ideal mixing as discussed above so that the loops reproduce those $\mathrm{Si}$ partitioning data. Indeed, Alfe et al. (2002) discussed that the deviation from ideal mixing is weak at low Si content.

The parameters for pure Fe melting were from Komabayashi (2014). The entropy changes upon melting for the end-member $\mathrm{Si}\left(\Delta S_{\mathrm{Si}}^{\text {melting }}\right)$ with the fcc and hcp structures at 1 bar were obtained from Dinsdale (1991) and I applied them to high-pressure melting at 60 (fcc) and 330 (hcp) GPa. The constant $\Delta S_{\mathrm{Si}}^{\text {melting }}$ without a phase change is supported by Richard's rule (a constant entropy change on melting for metals on the order of the gas constant) (e.g., Tiwari 1978). The end-member melting temperatures for $\mathrm{Si}\left(T_{\mathrm{Si}}^{\mathrm{melting}}\right)$ under high pressures were considered as follows. The $\Delta S^{\text {melting }}$ for both end-members are as large as $7-10 \mathrm{~J} / \mathrm{K} / \mathrm{mol}\left(\right.$ cf. $\Delta S_{\mathrm{Fe}}^{\mathrm{fcc}-\mathrm{hcp}}=3 \mathrm{~J} / \mathrm{K} / \mathrm{mol}$ at $60 \mathrm{GPa}$ ) (Table 1). Yamasaki and Banno (1972) analysed effects of $\Delta S$ for the end-members on the shape of a two-phase loop in a binary system (Fig. 3). Assuming both phases are ideal solutions, when $\Delta S$ is large for both end-members, a phase transition loop would be wide, depending on the difference in transition temperature between the end-members, i.e., $\Delta T_{\mathrm{Fe} \text { - } \mathrm{Si}}^{\mathrm{mi}}$ for the present discussion (Fig. 3). As such $\Delta T_{\mathrm{Fe}-\mathrm{Si}}^{\mathrm{melting}}$ needs to be small in order to account for the reported narrow melting loops. Since $T_{\mathrm{Fe}}^{\mathrm{melting}}$ was rather well constrained by the thermodynamic database (Komabayashi 2014), the width of the calculated melting loop can be narrowed to fit the reported Si partitioning data only if $T_{\mathrm{Si}}^{\text {melting }}$ is close to $T_{\mathrm{Fe}}^{\text {melting }}$.

When the melting phase loop was calculated to match the data by Ozawa et al. (2016) at $60 \mathrm{GPa}, T_{\mathrm{Si}}^{\text {melting }}$ needed to be $2600 \mathrm{~K}$ (Fig. 4a) which is only $300 \mathrm{~K}$ lower than $T_{\mathrm{Fe}}^{\text {melting }}=2910 \mathrm{~K}$. Alfe et al. (2002) concluded that $\mathrm{Si}$ is almost equally partitioned between solid and liquid to

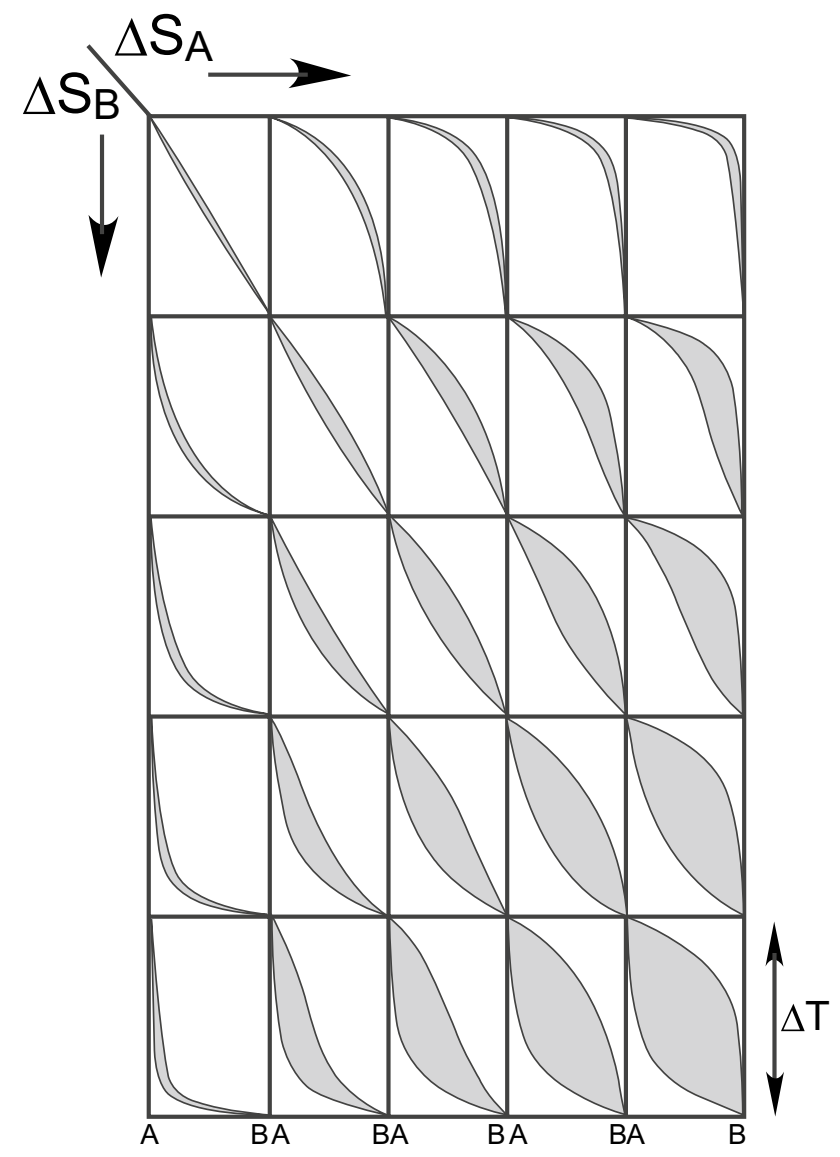

Fig. 3 Variation in the shape of a two-phase loop in the binary system $\mathrm{AB}$ as a function of $\Delta S_{\mathrm{A}}$ and $\Delta S_{\mathrm{B}}$ (after Yamasaki and Banno 1972). Ideal mixing is assumed. When both $\Delta S$ are large, the loop is wide, unless $\Delta T$ is small

$20 \mathrm{~mol} \% \mathrm{Si}(11 \mathrm{wt} \% \mathrm{Si})$ at $7000 \mathrm{~K}$ and $370 \mathrm{GPa}$. Assuming an ideal solution for both liquid and solid, an equal partitioning of Si between solid and liquid implies composition-independent melting, which is expressed as a single horizontal line in Fig. 4b (green line). To investigate the sensitivity of the width of the phase loop to $T_{\mathrm{Si}}^{\text {melting }}$ and to provide a guide for future experiments, I calculated the melting loops at $330 \mathrm{GPa}$ assuming a minimum fractionation detectable by experiment (ca. \pm 0.3 wt $\% \mathrm{Si}$ at $\mathrm{Fe}-6 \mathrm{wt} \% \mathrm{Si}$ ) (Fig. 4b, black line). The results showed that $T_{\mathrm{Si}}^{\text {melting }}$ was between 6100 and $6660 \mathrm{~K}$ when $T_{\mathrm{Fe}}^{\text {melting }}$ was $6380 \mathrm{~K}$. As such, the small fractionation of Si would hardly change the liquidus temperature and the melting temperature in the Fe-rich region of the phase diagram may be essentially composition independent. Note that here I only discussed the melting temperatures of the Fe-Si hcp phases at $330 \mathrm{GPa}$ and the eutectic relations shown in Fig. $4 \mathrm{~b}$ needs to be examined by experiment and first-principles calculation because there are no reports of direct measurements. In particular, the eutectic 

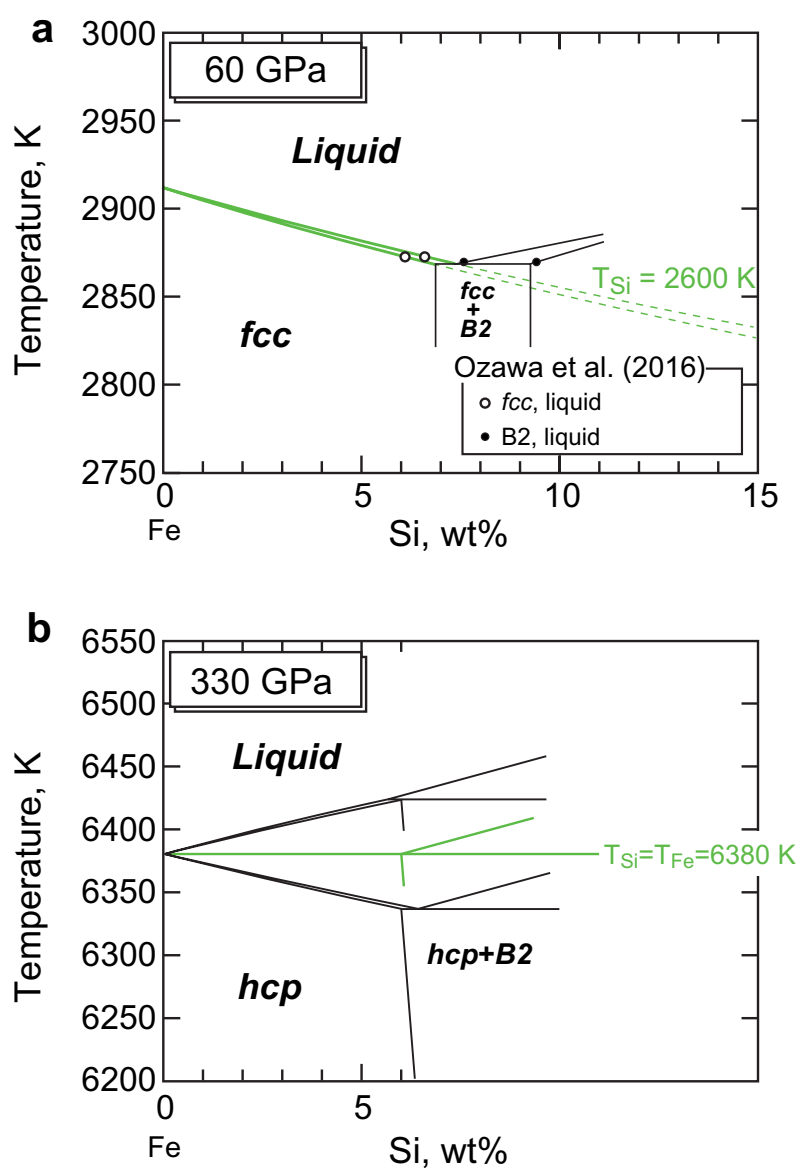

Fig. 4 Calculated melting loops of $\mathbf{a}$ the fcc and $\mathbf{b}$ hcp phases at 60 and $330 \mathrm{GPa}$ respectively, with ideal mixing assumed between $\mathrm{Fe}$ and $\mathrm{Si}$. The green lines were obtained so that the calculations reproduce the reported Si partitioning data (Ozawa et al. 2016; Alfe et al. 2002). At both pressure conditions, inferred eutectic relations were also drawn. The used parameters are listed in Table 1 . In a, Si partitioning data between the liquid and B2 phases are also plotted (Ozawa et al. 2016). In b, the hcp melting line in green corresponds to the equal Si partitioning (Alfe et al. 2002). The black lines represent the present calculations assuming a small, i.e., experimentally detectable fractionation of $\mathrm{Si}$ (ca. $\pm 0.3 \mathrm{wt} \% \mathrm{Si}$ at $\mathrm{Fe}-6 \mathrm{wt} \% \mathrm{Si}$ ), resulting in $T_{\mathrm{Si}}^{\text {melting }}=6100$ and $6660 \mathrm{~K}$ when $T_{\mathrm{Fe}}^{\text {melting }}$ was $6380 \mathrm{~K}$. The melting temperatures of the Fe-Si hcp phases are only discussed in $\mathbf{b}$ and the eutectic compositions at about 6 wt $\% \mathrm{Si}$ were tentatively assumed based on the subsolidus phase relations (Tateno et al. 2015)

compositions were assumed to be about Fe- 6 wt $\%$ Si from the only experimental constraint of a subsolidus reaction between hcp and hcp + B2 occurring at $4750 \mathrm{~K}$ at $330 \mathrm{GPa}$ for Fe-9 wt\%Si (Tateno et al. 2015). The parameters used in the calculations are listed in Table 1.

For 1-8 wt\%Si-bearing iron systems, which span the proposed values for the Si content in Earth's core (Wade and Wood 2005; Antonangeli et al. 2010; Rubie et al. 2011; Badro et al. 2015; Antonangeli et al. 2018), the expected change of liquidus temperature of $\mathrm{Fe}$ due to $\mathrm{Si}$ is about $-50 \mathrm{~K}$ at $60 \mathrm{GPa}$ and about $0 \mathrm{~K}$ at $330 \mathrm{GPa}$ (Fig. 4). This

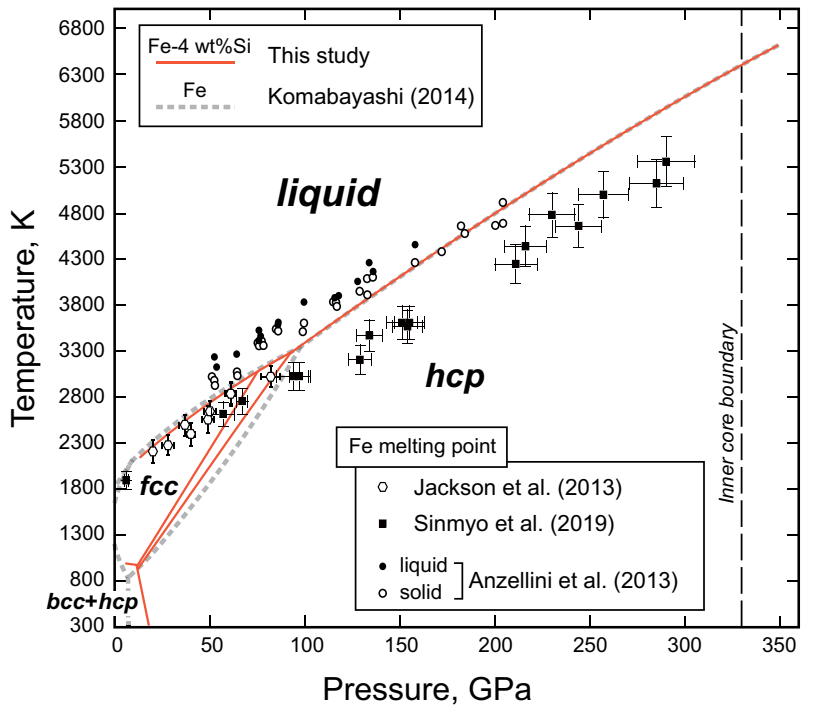

Fig. 5 A phase diagram for $\mathrm{Fe}-4 \mathrm{wt} \% \mathrm{Si}$ in comparison to that of pure iron (Komabayashi 2014). The fcc-hcp transition boundaries and melting curve of the hcp phase were calculated with ideal mixing of $\mathrm{Fe}$ and $\mathrm{Si}$, while the other boundaries including the melting curve of the fcc phase were schematically drawn. The melting curves of the fcc and hcp phases are compared with of pure Fe (Komabayashi 2014), namely, $20 \mathrm{~K}$ lower than pure iron at $60 \mathrm{GPa}$ and the same as for iron above $90 \mathrm{GPa}$. Pure iron melting data by experiment are plotted (Anzellini et al. 2013; Jackson et al. 2013; Sinmyo et al. 2019)

suggests that the addition of Si to Earth's core would not significantly affect the temperature at the ICB where the inner core is believed to be crystallised from the outer core.

\section{Discussions}

\section{Phase diagram and liquid EoS of Fe-4 wt\%Si}

Figure 5 shows a phase diagram of Fe- 4 wt $\% \mathrm{Si}$ to the ICB condition. As discussed above the width of the melting loop is very narrow above $60 \mathrm{GPa}$ and I will not distinguish liquidus and solidus in the following discussions. The difference in melting point between the alloy and pure Fe is very small at $60 \mathrm{GPa}$ and diminishes with increasing pressure, which places tight constraints on the $P-T$ location of the melting curves of $\mathrm{Fe}-4 \mathrm{wt} \% \mathrm{Si}$ from 60 to $360 \mathrm{GPa}$.

A melting curve constrained over a wide $P-T$ range can be used to deduce a thermal EoS for the liquid phase when the other thermodynamic parameters are available including the EoS of the subsolidus crystalline phase (Komabayashi 2014). A high-pressure phase equilibrium relation can be calculated based on the Gibbs free energy of phases as a function of $P$ and $T$. The Gibbs free energy of a phase at a given $P-T$ condition is expressed as: 
$G=G_{1 \mathrm{bar}, T}+\int_{1 \mathrm{bar}}^{P} V_{T} \mathrm{~d} P$

where $G_{1 \mathrm{bar}, T}$ is the Gibbs free energy at 1 bar and $T$ of interest and $V_{T}$ is the molar volume at $T$. The volumetric term in Eq. (8) is calculated from a $P-V-T E o S$ of the phase. In this study, the room-temperature volume is expressed with the Vinet EoS as:

$P_{298}=3 K_{0} x^{-2}(1-x) \exp \left[\frac{3}{2}\left(K^{\prime}-1\right) *(1-x)\right]$

where $x \equiv\left(V / V_{0}\right)^{1 / 3}$ and, $P_{298}, K_{0}, K^{\prime}$, and $V_{0}$ are the pressure at $298 \mathrm{~K}$, the isothermal bulk modulus, its pressure derivative, and the molar volume at the reference $P-T$ conditions of 1 bar and $298 \mathrm{~K}$, respectively.

The thermal expansion of a phase under high pressure was formulated using the Anderson-Grüneisen parameter, $\delta_{T}$ (Anderson et al. 1992): $\frac{\partial \ln \alpha}{\partial \ln V}=\delta_{\mathrm{T}}=\delta_{0} \eta^{\kappa}$

where $\eta \equiv V / V_{0}, \delta_{0}$ is the value of $\delta_{T}$ at 1 bar and $\kappa$ is a dimensionless parameter. This equation yields:

$\frac{\alpha}{\alpha_{0}}=\exp \left[-\frac{\delta_{0}}{\kappa}\left(1-\eta^{\kappa}\right)\right]$

where $\alpha_{0}$ is the thermal expansivity at 1 bar.

$G_{1 \text { bar, T }}$ was obtained from ideal mixing of the endmember phases (Komabayashi 2014; Dinsdale 1991) (Table 2). The EoS parameters for the Fe-4 wt \% Si hcp phase were evaluated in Komabayashi et al. (2019) based on the parameters of the pure Fe (Dewaele et al. 2006) and of Fe-9 wt\%Si (Tateno et al. 2015). I have evaluated the EoS parameters for the $\mathrm{Fe}-4 \mathrm{wt} \% \mathrm{Si}$ liquid phase by calculating the melting curve which reproduces that of the pure Fe hcp phase at 100-350 GPa (Komabayashi 2014). The obtained parameters are listed in Table 3.

Table 2 Gibbs energies of pure phases $\left({ }^{\circ} G\right)$ at 1 bar, $T\left(\mathrm{~J} \cdot \mathrm{mol}^{-1}\right)=a+b T+c T \ln T+d T^{2}+e T^{-1}+f T^{0.5}+g \mathrm{~T}^{-9}$

\begin{tabular}{llllllll}
\hline Phase & $a$ & $b$ & $c$ & $d$ & $e$ & $f$ & $g$ \\
\hline fcc iron $^{\mathrm{a}}$ & $16,300.921$ & 381.47162 & -52.2754 & 0.000177578 & $-395,355.43$ & -2476.28 & 0 \\
hcp iron $^{\mathrm{b}}$ & $12,460.921$ & 386.99162 & -52.2754 & 0.000177578 & $-395,355.43$ & -2476.28 & 0 \\
Liquid iron $^{\mathrm{c}}$ & -9007.3402 & 290.29866 & -46 & 0 & 0 & 0 & 0 \\
fcc silicon $^{\mathrm{d}}$ & $41,542.358$ & 145.481367 & -27.196 & 0 & 0 & 0 & $-4.2037 \mathrm{E} 30$ \\
hcp silicon $^{\mathrm{e}}$ & $39,742.358$ & 146.481367 & -27.196 & 0 & 0 & 0 & $-4.2037 \mathrm{E} 30$ \\
Liquid silicon $^{\mathrm{f}}$ & $40,370.523$ & 137.722298 & -27.196 & 0 & 0 & 0 \\
\hline
\end{tabular}

${ }^{a}$ fcc iron: Komabayashi (2014); Saxena and Dubrovinsky (1998)

bhcp iron: Komabayashi (2014)

${ }^{c}$ Liquid iron: Komabayashi (2014); Saxena and Dubrovinsky (1998)

${ }^{\mathrm{d}}$ fcc silicon: Dinsdale (1991)

${ }^{\mathrm{e}}$ hcp silicon: Dinsdale (1991)

${ }^{\mathrm{f}}$ Liquid silicon: Dinsdale (1991)

Table 3 Thermophysical parameters in the VinetAnderson-Grüneisen equation

\begin{tabular}{lclllll}
\hline Phase & $V_{0}\left(\mathrm{~cm}^{3} \mathrm{~mol}^{-1}\right)$ & $K_{0}(\mathrm{GPa})$ & $K^{\prime}$ & $\alpha_{0}\left(* 10^{-5} \mathrm{~K}^{-1}\right)$ & $\delta_{0}$ & $\kappa$ \\
\hline FCC iron $^{\mathrm{a}}$ & 6.82 & 163.4 & 5.38 & 7 & 5.5 & 1.4 \\
hcp iron $^{\mathrm{b}}$ & 6.753 & 163.4 & 5.38 & 5.8 & 5.1 & 1.4 \\
hcp Fe-4wt \% Si $^{\mathrm{c}}$ & 6.791 & 165.5 & 5.44 & 5.8 & 5.1 & 1.4 \\
Liquid iron $^{\mathrm{d}}$ & 6.880 & 148.0 & 5.8 & 9.0 & 5.1 & 0.56 \\
Liquid FeO $^{\mathrm{e}}$ & 13.16 & 128.0 & 3.85 & 4.7 & 4.5 & 1.4 \\
Liquid Fe-4 wt\%Sif & 6.909 & 150.3 & 5.81 & 9.0 & 5.1 & 0.56 \\
\hline
\end{tabular}

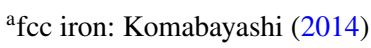

${ }^{b}$ hcp iron: Refitted to the data of Dewaele et al. (2006) by Komabayashi (2014)

${ }^{\mathrm{c}}$ hcp Fe-4 wt\%Si: Refitted to the data of Komabayashi et al. (2019)

${ }^{\mathrm{d}}$ Liquid iron: Komabayashi (2014)

éLiquid FeO: Komabayashi (2014)

${ }^{\mathrm{f}}$ Liquid $\mathrm{Fe}-4 \mathrm{wt} \% \mathrm{Si}$ : all parameters were assessed in this study 
The melting of the Fe-4 wt $\%$ Si hcp phase at the ICB is accompanied with a volume change of $1.6 \%$, which is slightly smaller than the case of pure $\mathrm{Fe}$ of $2.0 \%$. Selected thermodynamic properties for the hcp and liquid phases of $\mathrm{Fe}-4 \mathrm{wt} \% \mathrm{Si}$ are presented in Table S1.

The derivation of the EoS of the Fe-Si liquid phase presented above depends on the choice of melting curves of iron. The high-pressure melting curve of iron used in this study was from Komabayashi (2014) which is consistent with experimental data of Anzellini et al. (2013) and Jackson et al. (2013). Very recently a new melting curve of iron was proposed by Sinmyo et al. (2019) on the basis of high- $P-T$ experiment. Those high-pressure melting data by experiment are shown in Fig. 5 for comparison. Sinmyo et al. (2019)'s melting points are systematically lower than Anzellini et al. (2013)'s data. If one models an EoS for liquid iron using Sinmyo et al. (2019)'s melting curve, its resulting density will be greater than the case of Komabayashi (2014)'s melting curve. However incorporation of the new data into the thermodynamic model needs very careful treatment as the model by Komabayashi (2014) is consistent with many different types of measurements. For example, Komabayashi (2014)'s database, starting with the 1 bar metallurgy data, is consistent with phase relations in the system $\mathrm{Fe}-\mathrm{FeO}$ determined in multianvil apparatus (e.g., Tsuno et al. 2007) and melting points of fcc iron (Jackson et al. 2013) and of hcp iron (Anzellini et al. 2013) determined in DACs. Also, the eutectic melting relationships of $\mathrm{Fe}-\mathrm{FeO}$ at high pressures calculated by Komabayashi (2014) using Frost et al. (2010)'s mixing model were recently confirmed by a DAC experiment by Oka et al. (2019). In addition, the entropy change on melting of iron in Komabayashi (2014) follows Richard's rule along the melting curve. As such the phase relations calculated by Komabayashi (2014) are consistent with many experimental data using the DAC and multianvil, and of 1 bar measurements. Furthermore, the validity of his EoS for liquid iron was confirmed by the firstprinciples calculation to 2 terapascals and 10,000 K (Wagle and Steinle-Neumann 2019 and reference therein). As such, the Fe database of Komabayashi (2014) has been tested and validated. The newly proposed melting curve of iron by Sinmyo et al. (2019) will have to be tested by comparing with those different types of measurements in the future.

\section{Liquids in the system $\mathrm{Fe}-\mathrm{Si}-\mathrm{O}$ and silicon and oxygen in the core}

Silicon and oxygen are considered to be major light elements in the core as a consequence of metal-silicate partitioning in the magma ocean during core formation. Although the seismic velocity and density of $\mathrm{Si}$ - and O-bearing Fe liquids were examined and possible ranges for their amounts in the core were proposed by first-principles calculation (Badro et al. 2014), there is no such a model reported from experimental data sources. Here I predict the nature of $\mathrm{Si}$ and O-bearing outer cores from the thermodynamic models of $\mathrm{Fe}-\mathrm{FeO}$ (Komabayashi 2014) and $\mathrm{Fe}-\mathrm{Si}$ (this study) which are based on experimental data.

Komabayashi (2014) discussed that the liquids of the system $\mathrm{Fe}$ and $\mathrm{FeO}$ can be modelled with ideal mixing of the end-member liquids under core $P-T$ conditions. This study has shown that mixing of $\mathrm{Fe}$ and $\mathrm{Si}$ liquids can be represented by ideal mixing as well. I therefore assume that mixing of $\mathrm{Fe}, \mathrm{FeO}$, and $\mathrm{Si}$ liquids would be ideal mixing under core $P-T$ conditions. This enables us to compare the physical properties of iron liquids and resulting core composition with those by theory (Badro et al. 2014) which placed the same assumption on the ideality of mixing liquids in the system $\mathrm{Fe}-\mathrm{Si}-\mathrm{O}$ for Earth's core. A more recent theoretical work reported that Fe-rich liquids in the same ternary system would indeed behave as ideal solutions under core conditions (Huang et al. 2019). As Komabayashi (2014) demonstrated, the ideality of liquids can be tested by comparing calculated phase relations with experimental data, such as eutectic temperature, which should be made in the near future. Below I discuss the isentrope, density, and $\mathrm{Vp}$ of hypothetical outer cores in the systems $\mathrm{Fe}-\mathrm{Si}$ and $\mathrm{Fe}-\mathrm{Si}-\mathrm{O}$.

Figure 6 shows isentropes of the outer cores with compositions of Fe (Komabayashi 2014), Fe-5.9 wt\%O (Komabayashi 2014), Fe-4 wt\% Si (this study), and Fe-5.8 wt $\% \mathrm{Si}-0.8 \mathrm{wt} \% \mathrm{O}$ (this study, see below). Each isentrope starts at the liquidus temperature of the respective

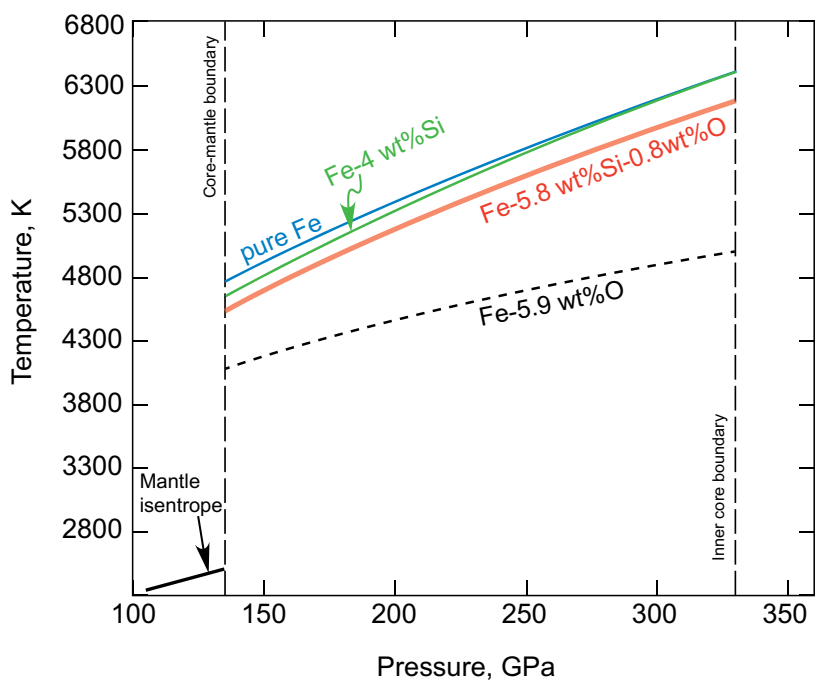

Fig. 6 Isentropic temperature profiles of $\mathrm{Fe}-4$ wt $\% \mathrm{Si}$ and $\mathrm{Fe}-5.8$ wt $\% \mathrm{Si}-0.8$ wt $\% \mathrm{O}$ outer cores. Reported profiles of outer cores with pure $\mathrm{Fe}$ and $\mathrm{Fe}-5.9$ wt\%O (Komabayashi 2014) are also shown. The mantle profile is from Brown and Shankland (1981) 
composition at the ICB. I assume the liquidus temperature of the system $\mathrm{Fe}-\mathrm{Si}-\mathrm{O}$ is the same as of $\mathrm{Fe}-\mathrm{FeO}$ since the addition of $\mathrm{Si}$ would not change the liquidus temperature under the core pressures. The temperatures at the coremantle boundary (CMB) are $4750 \mathrm{~K}$ for Fe; $4070 \mathrm{~K}$ for $\mathrm{Fe}-5.9 \mathrm{wt} \% \mathrm{O} ; 4660 \mathrm{~K}$ for Fe-4 wt\% $\mathrm{Si} ; 4560 \mathrm{~K}$ for Fe-5.8 wt $\% \mathrm{Si}-0.8 \mathrm{wt} \% \mathrm{O}$. The Fe-4 wt $\% \mathrm{Si}$-outer core shows a very similar isentrope to that of the pure Fe core due to similar Grüneisen parameters (Table S1) (Komabayashi 2014). As such the thermal structure of the core would not be greatly affected by the presence of silicon.

Figure 7 shows calculated density and $\mathrm{Vp}$ for each outer core composition along its isentrope together with seismologically constrained values (PREM, Dziewonski and Anderson 1981). Pure iron shows greater density and slower velocity than the PREM (Anderson and Ahrens 1994; Komabayashi 2014). The addition of silicon increases the velocity, contrary to the case of oxygen. Figure 8 plots the $\mathrm{Si}$ and $\mathrm{O}$ contents which satisfy the Vp or density of the PREM. The intersection of the $\mathrm{Vp}$ - and density-satisfying lines yields the best-fit solution of Fe-5.8(0.6) wt $\% \mathrm{Si}-0.8(0.6) \mathrm{wt} \% \mathrm{O}$, taking the errors for density $(0.2 \%$ from $\mathrm{EoS}$ and $0.5 \%$ from observation) and velocity ( $0.2 \%$ from EoS and $0.2 \%$ from observation) into account. As discussed in Komabayashi (2014), oxygen may not be the primary light element in the core mostly due to its distinctive nature reducing the velocity of liquid iron alloy. Selected thermodynamic properties for the best-fit outer core at the CMB and ICB are presented in Table 4.

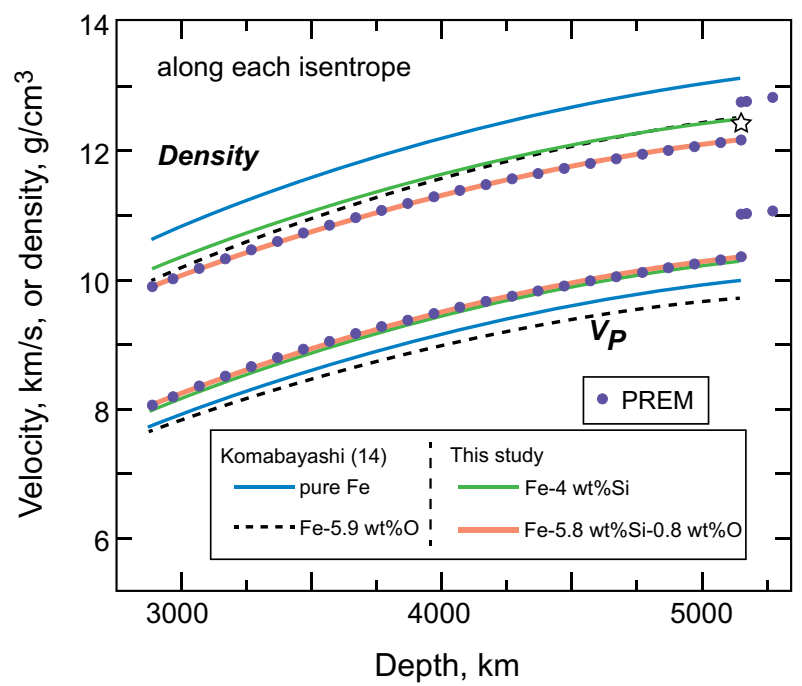

Fig. 7 -wave velocities (Vp) and densities of iron alloys: pure $\mathrm{Fe}$ (Komabayashi 2014), Fe-5.9 wt\%O (Komabayashi 2014), Fe-4 wt\% Si (this study), and $\mathrm{Fe}-5.8 \mathrm{wt} \% \mathrm{Si}-0.8 \mathrm{wt} \% \mathrm{O}$ (this study). Each profile was along its isentrope (Fig. 6). The star represents the density of the $\mathrm{Fe}-\mathrm{Si}$ hcp phase which would precipitate from the Fe-5.8 wt $\% \mathrm{Si}-0.8$ wt $\% \mathrm{O}$ outer core

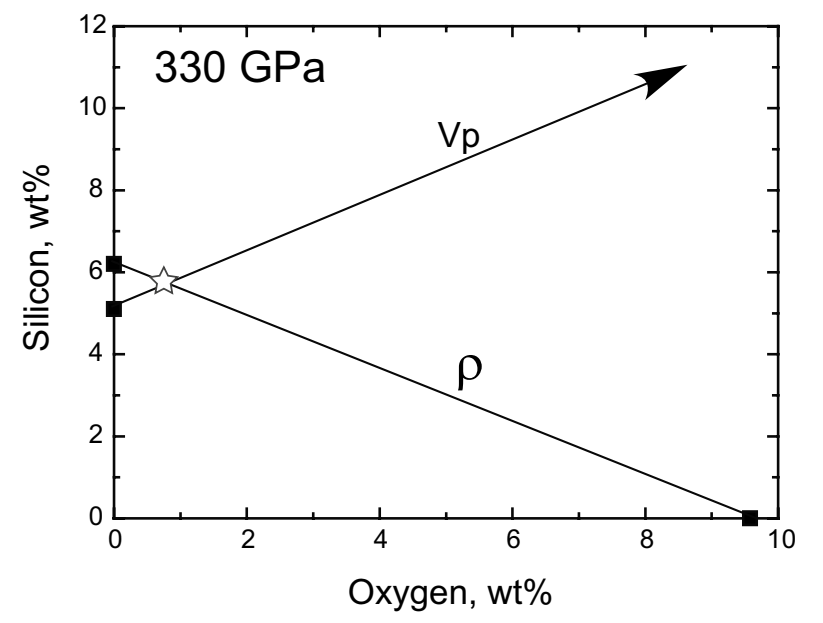

Fig. 8 The amounts of silicon and oxygen which satisfy the velocity $(\mathrm{Vp})$ or density $(\rho)$ of the PREM for the outer core at $330 \mathrm{GPa}$. The temperature is at the liquidus temperature for each composition, projected onto the system $\mathrm{Fe}-\mathrm{FeO}$ (Komabayashi 2014). The star indicates the best-fit outer core composition, Fe-5.8 wt $\% \mathrm{Si}-0.8$ wt $\% \mathrm{O}$

The best-fit composition of the outer core is close to the binary system $\mathrm{Fe}-\mathrm{Si}$ and here I compare it with earlier estimates in the system Fe-Si. Fischer et al. (2014) and Tateno et al. (2015) estimated the Si content in the outer core based on compression experiments on Fe- $9 \mathrm{wt} \% \mathrm{Si}$ hcp phases, assuming silicon is the sole light element there. Figure 8 shows that the $\mathrm{Si}$ content in an $\mathrm{Fe}-\mathrm{Si}$ liquid needed to reconcile the PREM density is $6.2 \mathrm{wt} \%$ in my model. This value should be consistent with the data in Tateno et al. (2015) as the EoS of the Fe-Si hcp phase in this study was evaluated based on their data (Komabayashi et al. 2019). On the other hand, Fischer et al. (2014)'s estimate of the Si content in the outer core was about $11 \mathrm{wt} \%$. The outer core thermal profile in Fischer et al. (2014) assumed $4000 \mathrm{~K}$ at the CMB, indicating 600-700 K lower than in this study, corresponding to a density difference of about $1 \%$. Furthermore, the density change upon melting of iron at the CMB pressure is $2.6 \%$ (Komabayashi 2014) while Fischer et al. (2014) assumed between 1 and 2\%. Adding all these factors up will reduce the estimated $\mathrm{Si}$ content in the outer core with Fischer et al. (2014)'s model to about $9 \mathrm{wt} \%$, which is $3 \%$ different from the case of this study. The remaining unresolved factor likely lies in the thermal pressure term in the EoS of the Fe-Si hcp phases as the experiments in Fischer et al. (2014) and Tateno et al. (2015) were based on different pressure scales. Note that all the data in Komabayashi (2014) and Komabayashi et al. (2019) were based on pressure scales consistent with Tateno et al. (2015).

Badro et al. (2014) also predicted the effects of several light elements on the density and velocity of iron liquid from the first-principles calculations and proposed a 
Table 4 Calculated physical properties of $\mathrm{Fe}-\mathrm{Si}-\mathrm{O}$ liquids

\begin{tabular}{|c|c|c|c|c|c|c|c|c|}
\hline $\begin{array}{l}P \\
\mathrm{GPa}\end{array}$ & $\begin{array}{l}T \\
\mathrm{~K}\end{array}$ & Composition & $\begin{array}{l}V \\
\mathrm{~cm}^{3} \mathrm{~mol}^{-1}\end{array}$ & $\begin{array}{l}K_{T} \\
\mathrm{GPa}\end{array}$ & $\begin{array}{l}\alpha \\
* 10^{-5} \mathrm{~K}^{-1}\end{array}$ & $\begin{array}{l}S \\
\mathrm{~J} \mathrm{~K}^{-1} \mathrm{~mol}^{-1}\end{array}$ & $\gamma^{\mathrm{b}}$ & $\begin{array}{l}\mathrm{Vp} \\
\mathrm{km} \mathrm{s}^{-1}\end{array}$ \\
\hline \multirow[t]{4}{*}{136} & 4000 & $\mathrm{Fe}$ & 5.182 & 587 & 1.78 & 104.3 & 1.52 & 7.77 \\
\hline & & $\mathrm{Fe}-5.9 \mathrm{wt} \% \mathrm{O}$ & 4.871 & 551 & 1.54 & 108.7 & 1.07 & 7.67 \\
\hline & & $\mathrm{Fe}-4 \mathrm{wt} \% \mathrm{Si}$ & 5.224 & 589 & 1.81 & 104.4 & 1.63 & 8.00 \\
\hline & & $\mathrm{Fe}-5.8 \mathrm{wt} \% \mathrm{Si}-0.8 \mathrm{wt} \% \mathrm{O}$ & 5.199 & 584 & 1.79 & 104.3 & 1.60 & 8.08 \\
\hline \multirow[t]{4}{*}{330} & 6000 & $\mathrm{Fe}^{\mathrm{a}}$ & 4.250 & 1224 & 0.86 & 108.4 & 1.39 & 9.99 \\
\hline & & $\mathrm{Fe}-5.9 \mathrm{wt} \% \mathrm{O}$ & 3.914 & 1122 & 0.79 & 116.5 & 0.86 & 9.69 \\
\hline & & $\mathrm{Fe}-4 \mathrm{wt} \% \mathrm{Si}^{\mathrm{a}}$ & 4.288 & 1227 & 0.88 & 107.5 & 1.51 & 10.28 \\
\hline & & $\mathrm{Fe}-5.8 \mathrm{wt} \% \mathrm{Si}-0.8 \mathrm{wt} \% \mathrm{O}$ & 4.258 & 1214 & 0.87 & 107.6 & 1.46 & 10.35 \\
\hline
\end{tabular}

$K_{T}$ isothermal bulk modulus

${ }^{\mathrm{a}} 6000 \mathrm{~K}$ at $330 \mathrm{GPa}$ is below the melting points for $\mathrm{Fe}$ and $\mathrm{Fe}-4 \mathrm{wt} \% \mathrm{Si}$

${ }^{\mathrm{b}} \gamma$, Grüneisen parameter which is given by $\gamma=\alpha \mathrm{VK}_{\mathrm{T}} / \mathrm{Cv}$, where $\mathrm{Cv}$ is the heat capacity at constant volume

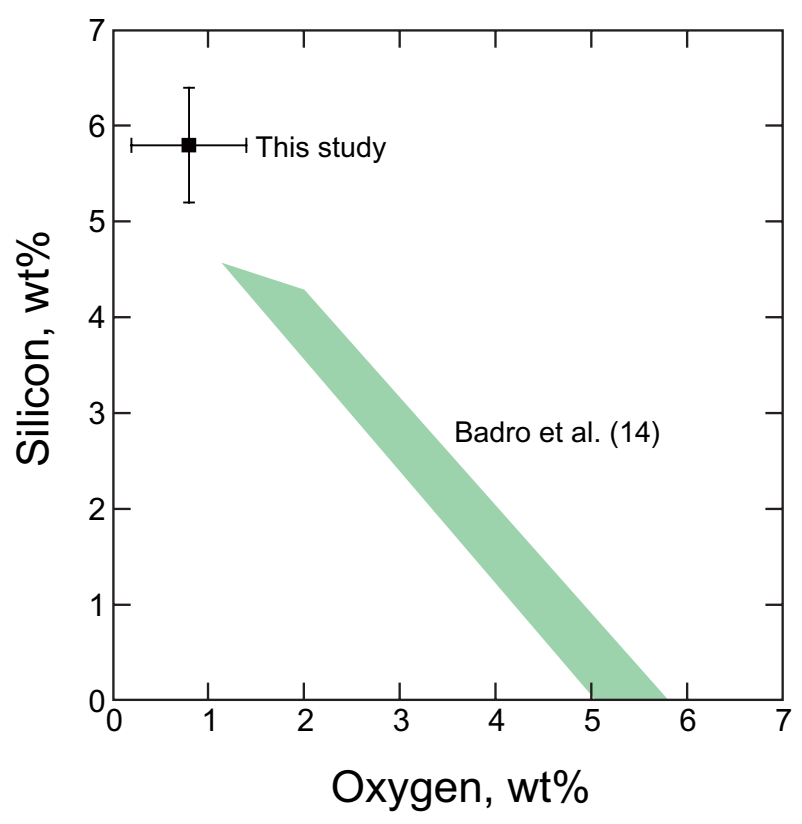

Fig. 9 The silicon and oxygen contents in the outer core which match the density and Vp of the PREM (Figs. 7 and 8). The reported range for the $\mathrm{Si}$ and $\mathrm{O}$ contents in an $\mathrm{Fe}-\mathrm{Ni}$ outer core from the first-principles calculations is shown as the green area (Badro et al. 2014)

seismologically consistent compositional range for the outer core. Figure 9 compares the results of this study with the range of $\mathrm{Si}$ and $\mathrm{O}$ contents in $\mathrm{Fe}-\mathrm{Ni}$ core melt by Badro et al. (2014). The outer core composition of this study is placed slightly outside their range which was up to $4.5 \mathrm{wt} \% \mathrm{Si}$ at the minimum oxygen content of $1.2 \mathrm{wt} \%$. The major source for the discrepancy lies in the effect of oxygen on the velocity of iron liquid. Figure 10 shows the effects of silicon and oxygen on the liquid iron properties: density, adiabatic bulk modulus, and Vp. Komabayashi (2014)'s model predicted a negative effect (i.e., decrease) on the velocity by the addition of oxygen while Badro et al. (2014)'s model predicted
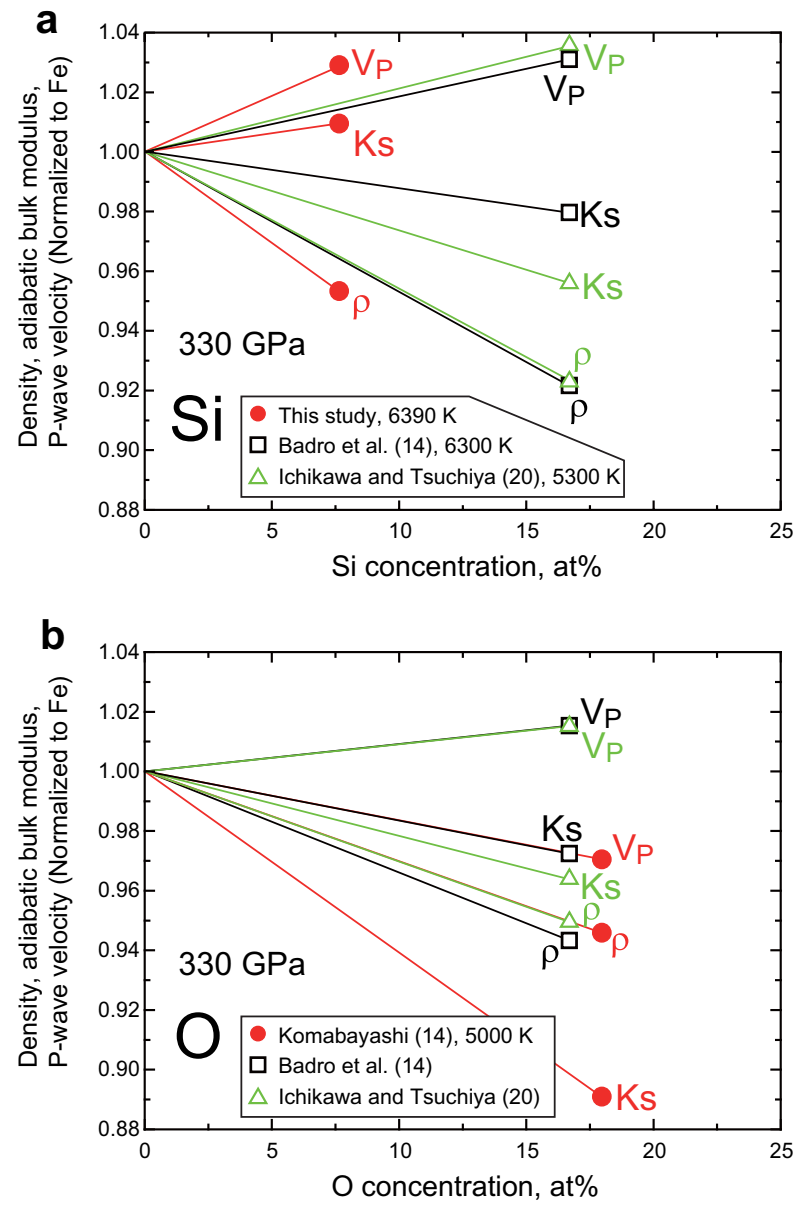

Fig. 10 Effects of a silicon and $\mathbf{b}$ oxygen on the $P$-wave velocity $(\mathrm{Vp})$, adiabatic bulk modulus (Ks) and density $(\rho)$ of liquid iron at $330 \mathrm{GPa}$. Data from the first principles studies are compared (Badro et al. 2014; Ichikawa and Tsuchiya 2020). Note that the parameters are normalized to those for pure iron. The effect of oxygen on Ks is more pronounced than on $\rho$, resulting in a reduction of $\mathrm{Vp}$ (this study; Komabayashi 2014) 
a positive effect. Another recent first-principle calculations by Ichikawa and Tsuchiya (2020) predicted similar trends to those in Badro et al. (2014) (Fig. 10). However, this does not necessarily indicate that the experiment-based and theorybased models are complete opposite. The result depends on the magnitude of reduction of the bulk modulus of iron liquid due to oxygen. All Badro et al. (2014), Komabayashi (2014), and Ichikawa and Tsuchiya (2020) show that the addition of oxygen reduces both the bulk modulus and density (Fig. 10b). The Vp is reduced in Komabayashi (2014) because the bulk modulus decreases more than density by mixing an oxygen component. This indicates that increase/ decrease of $\mathrm{Vp}$ depends on the difference in the elastic parameter between the end-members [i.e., $\mathrm{Fe}$ and $\mathrm{FeO}$ in Komabayashi (2014)]. In his modelling of the EoS of liquid phases, Komabayashi (2014) demonstrated that the compressibility of a liquid should be close to that of the counterpart crystalline phase under core pressures, and the small bulk modulus of liquid $\mathrm{FeO}$ was a consequence of a small bulk modulus of solid B1 FeO. The EoS of solid B1 FeO was established based on experimental data to $207 \mathrm{GPa}$ and $3800 \mathrm{~K}$ (Fischer et al. 2011; Ozawa et al. 2010) which are relevant to core conditions and therefore its elastic behaviour can be reliably applied.

Similarly the effects of silicon on the bulk modulus are in contrast between the experiment-based (this study) and theory-based models (Badro et al. 2014; Ichikawa and Tsuchiya 2020) although all the papers show positive effects on the Vp (Fig. 10a). The EoS parameters for the $\mathrm{Fe}-\mathrm{Si}$ hcp phase in this study was based on the compression experiments by Tateno et al. (2015) to $305 \mathrm{GPa}$ who demonstrated that the addition of silicon surely increases the bulk modulus of hcp iron. Table 3 lists a set of EoS for solids and liquids in the system $\mathrm{Fe}-\mathrm{Si}$ while the first-principles calculations did not provide such a self-consistent set of EoS for solids and liquids in the system $\mathrm{Fe}-\mathrm{Si}$ or $\mathrm{Fe}-\mathrm{O}$. Further comparison is needed to resolve the difference between experiment and theory.

The best-fit outer core composition in this study is here compared with previously proposed core compositions based on metal-silicate partitioning experiments which placed constraints on core formation processes. Si-rich and O-poor models were proposed by Wade and Wood (2005) (5-7 wt $\% \mathrm{Si}+0 \mathrm{wt} \% \mathrm{O})$ and Rubie et al. (2011) $(8 \mathrm{wt} \% \mathrm{Si}+0.5 \mathrm{wt} \% \mathrm{O})$, which are close to my best-fit outer core composition. In contrast, Siebert et al. (2013) proposed an O-rich core with a compositional range of $1.5-2.2 \mathrm{wt} \% \mathrm{Si}+4.5-5.5 \mathrm{wt} \% \mathrm{O}$. This oxygen-rich composition falls within the range of $\mathrm{Si}$ and $\mathrm{O}$ contents by Badro et al. (2014) in Fig. 9. Therefore, resolving the above-discussed discrepancy in the effects of $\mathrm{Si}$ and $\mathrm{O}$ on liquid iron properties will help to narrow down the possible core formation scenarios.
I also calculated the density of the hcp phase at $330 \mathrm{GPa}$ which would crystallise from the Fe-5.8 wt $\% \mathrm{Si}-0.8 \mathrm{wt} \% \mathrm{O}$ outer core melt, i.e., to form the inner core. As oxygen is not partitioned into hcp iron upon crystallization (Ozawa et al. 2010), the composition of the precipitating phase is going to be Fe-5.85 wt\%Si. From the EoS of hcp iron phases in the system Fe-Si (Dewaele et al. 2006; Tateno et al. 2015), the density of the crystallising phase at $330 \mathrm{GPa}$ and $6180 \mathrm{~K}$ is calculated to be $12.42 \mathrm{~g} / \mathrm{cm}^{3}$, which is much less dense than the inner core $\left(12.77 \mathrm{~g} / \mathrm{cm}^{3}\right)$ (Fig. 7). Therefore, while Fe-5.8 wt $\%$ Si-0.8 wt $\%$ can account for the seismic properties of the outer core, it does not produce a consistent inner core phase. This is mainly because the melting loop is very narrow and a significant amount of silicon is partitioned into the inner core upon crystallisation. On the other hand, Ozawa et al. (2016) proposed that the Si-rich B2 phase would crystallise in an $\mathrm{Fe}-\mathrm{Si}$ outer core as they reported a $\mathrm{Si}$-poor eutectic composition $(<1.5 \mathrm{wt} \% \mathrm{Si})$ at $127 \mathrm{GPa}$. As mentioned above, there have been no direct measurements on the eutectic composition in the system Fe-Si at $330 \mathrm{GPa}$, and the crystallising phase needs to be examined in the future studies. Nevertheless, since the B2 phase contains much more silicon than the hcp phase, it should be much less dense and cannot account for the inner core density either (Ozawa et al. 2016). Therefore, in either case, Earth's core cannot be fully represented by the system $\mathrm{Fe}-\mathrm{Si}-\mathrm{O}$ and it must include another light element although silicon and oxygen are likely major impurities (Wade and Wood 2005; Rubie et al. 2011; Siebert et al. 2013).

\section{Summary and conclusions}

In summary: (1) I have constructed a thermodynamic model for the fcc-hcp phase transition in the Si-bearing iron system based on experimental data; (2) the model suggests that mixing of $\mathrm{Si}$ and $\mathrm{Fe}$ can be represented by ideal mixing under high $P$ and $T$; (3) the melting temperature for the Si-bearing iron phases should be insensitive to the $\mathrm{Si}$ content, otherwise the melting phase loop would be too wide because of the large $\Delta S$ of melting for both end-members; (4) I have evaluated a thermal EoS for the Si-bearing iron liquid from the determined melting temperatures; (5) Assuming ideal mixing between Fe, $\mathrm{FeO}$, and $\mathrm{Si}$, the best-fit composition to the PREM density and velocity of the outer core is $\mathrm{Fe}-5.8 \mathrm{wt} \% \mathrm{Si}-0.8 \mathrm{wt} \% \mathrm{O}$; (6) the determined outer core composition however does not produce a consistent inner core phase; (7) Earth's core must contain another light element in addition to silicon and oxygen. 
Acknowledgements Discussions with D. Antonangeli, G. Morard, and R. Sinmyo on experimental data are much appreciated. D. Frost is thanked for insightful discussions on the thermodynamics of alloys. Two anonymous reviewers are acknowledged for their critical and constructive comments, which improved the quality of the paper. This research was supported by the European Research Council (ERC) Consolidator grant to TK (Earth core \#647723).

Open Access This article is licensed under a Creative Commons Attribution 4.0 International License, which permits use, sharing, adaptation, distribution and reproduction in any medium or format, as long as you give appropriate credit to the original author(s) and the source, provide a link to the Creative Commons licence, and indicate if changes were made. The images or other third party material in this article are included in the article's Creative Commons licence, unless indicated otherwise in a credit line to the material. If material is not included in the article's Creative Commons licence and your intended use is not permitted by statutory regulation or exceeds the permitted use, you will need to obtain permission directly from the copyright holder. To view a copy of this licence, visit http://creativecommons .org/licenses/by/4.0/.

\section{References}

Alfe D, Gillan MJ, Price GD (2002) Composition and temperature of the Earth's core constrained by combining ab initio calculations and seismic data. Earth Planet Sci Lett 195:91-98

Anderson WW, Ahrens TJ (1994) An equation of state for liquid iron and implications for the Earth's core. J Geophys Res 99:4273-4284

Anderson OL, Oda H, Isaak DG (1992) A model for the computation of thermal expansivity at high compression and high temperatures: $\mathrm{MgO}$ as an example. Geophys Res Lett 19:1987-1990

Antonangeli D, Siebert J, Badro J, Farber DL, Fiquet G, Morard G, Ryerson FJ (2010) Composition of the Earth's inner core from high-pressure sound velocity measurements in $\mathrm{Fe}-\mathrm{Ni}-\mathrm{Si}$ alloys. Earth Planet Sci Lett 295:292-296

Antonangeli D, Morard G, Paolasini L, Garbarino G, Murphy CA, Edmund E, Decremps F, Fiquet G, Bosak A, Mezouar M, Fei YW (2018) Sound velocities and density measurements of solid hcp-Fe and hcp-Fe-Si (9 wt \%) alloy at high pressure: constraints on the Si abundance in the Earth's inner core. Earth Planet Sci Lett 482:446-453

Anzellini S, Dewaele A, Mezouar M, Loubeyre P, Morard G (2013) Melting of iron at Earth's inner core boundary based on fast X-ray diffraction. Science 340:464-466

Asanuma H, Ohtani E, Sakai T, Terasaki H, Kamada S, Hirao N, Sata N, Ohishi Y (2008) Phase relations of Fe-Si alloy up to core conditions: implications for the Earth inner core. Geophys Res Lett 35:L12307. https://doi.org/10.1029/2008GL033863

Asanuma H, Ohtani E, Sakai T, Terasaki H, Kamada S, Kondo T, Kikegawa T (2010) Melting of iron-silicon alloy up to the coremantle boundary pressure: implications to the thermal structure of the Earth's core. Phys Chem Mineral 37:353-359

Badro J, Cote AS, Brodholt JP (2014) A seismologically consistent compositional model of Earth's core. Proc Natl Acad Sci USA 111:7542-7545

Badro J, Brodholt JP, Piet H, Siebert J, Ryerson FJ (2015) Core formation and core composition from coupled geochemical and geophysical constraints. Proc Natl Acad Sci USA $112: 12310-12314$
Brown JM, Shankland TJ (1981) Thermodynamic parameters in the earth as determined from seismic profiles. Geophys J R Astron Soc 66:579-596

Cemič L (2005) Thermodynamics in mineral sciences. Springer, Berlin, p 386

Dewaele A, Loubeyre P, Occelli F, Mezouar M, Dorogokupets PI, Torrent M (2006) Quasihydrostatic equation of state of iron above2 Mbar. Phys Rev Lett 97:215504

Dinsdale AT (1991) SGTE data for pure elements. Calphad-Comput Coupling Phase Diagr Thermochem 15:317-425

Dobson DP, Vocadlo L, Wood IG (2002) A new high-pressure phase of FeSi. Am Mineral 87:784-787

Dziewonski AM, Anderson DL (1981) Preliminary reference Earth model. Phys Earth Planet Inter 25:297-356

Fei Y, Brosh E (2014) Experimental study and thermodynamic calculations of phase relations in the $\mathrm{Fe}-\mathrm{C}$ system at high pressure. Earth Planet Sci Lett 408:155-162

Fischer RA, Campbell AJ, Shofner GA, Lord OT, Przemyslaw D, Prakapenka VB (2011) Equation of state and phase diagram of FeO. Earth Planet Sci Lett 304:496-502

Fischer RA, Campbell AJ, Reaman DM, Miller NA, Heinz DL, Dera P, Prakapenka VB (2013) Phase relations in the Fe-FeSi system at high pressures and temperatures. Earth Planet Sci Lett 373:54-64

Fischer RA, Campbell AJ, Caracas R, Reaman DM, Heinz DL, Dera $\mathrm{P}$, Prakapenka VB (2014) Equations of state in the $\mathrm{Fe}-\mathrm{FeSi}$ system at high pressures and tempeatures. J Geophys Res. https ://doi.org/10.1002/2013JB010898

Frost DJ, Asahara Y, Rubie DC, Miyajima N, Dubrovinsky LS, Holzapfel C, Ohtani E, Miyahara M, Sakai T (2010) Partitioning of oxygen between the Earth's mantle and core. J Geophys Res 115:B02202. https://doi.org/10.1029/2009JB006302

Guggenheim EA (1937) The theoretical basis of Raoult's law. T Faraday Soc 33:0151-0155

Huang DY, Badro J, Brodholt J, Li YG (2019) Ab initio molecular dynamics investigation of molten Fe-Si-O in earth's core. Geophys Res Lett 46:6397-6405

Ichikawa H, Tsuchiya T (2020) Ab initio thermoelasticity of liquid iron-nickel-light element alloys. Minerals 10:59. https://doi. org/10.3390/min 10010059

Jackson JM, Sturhahn W, Lerche M, Zhao JY, Toellner TS, Alp EE, Sinogeikin SV, Bass JD, Murphy CA, Wicks JK (2013) Melting of compressed iron by monitoring atomic dynamics. Earth Planet Sci Lett 362:143-150

Kanibolotsky DS, Bieloborodova OA, Kotova NV, Lisnyak VV (2003) Thermodynamics of liquid Fe-Si and Fe-Ge alloys. J Therm Anal Calorim 71:583-591

Komabayashi T (2014) Thermodynamics of melting relations in the system $\mathrm{Fe}-\mathrm{FeO}$ at high pressure: implications for oxygen in the Earth's core. J Geophys Res. https://doi.org/10.1002/2014J B010980

Komabayashi T, Fei Y, Meng Y, Prakapenka V (2009) In situ X-ray diffraction measurements of the $\gamma-\varepsilon$ transition boundary of iron in an internally-heated diamond anvil cell. Earth Planet Sci Lett 282:252-257

Komabayashi T, Pesce G, Morard G, Antonangeli D, Sinmyo R, Mezouar M (2019) Phase transition boundary between fcc and hcp structures in $\mathrm{Fe}-\mathrm{Si}$ alloy and its implications for terrestrial planetary cores. Am Mineral 104:94-99

Kubaschewski O (1993) In: Okamoto H (ed) Phase diagram of binary iron alloys. Ohio, ASM International, p 380

Kuwayama Y, Hirose K (2004) Phase relations in the system Fe-FeSi at $21 \mathrm{GPa}$. Am Mineral 89:273-276

Lin JF, Heinz DL, Campbell AJ, Devine JM, Shen GY (2002) Ironsilicon alloy in Earth's core? Science 295:313-315

Lord OT, Wann ETH, Hunt SA, Walker AM, Santangeli J, Walter MJ, Dobson DP, Wood IG, Vocadlo L, Morard G, Mezouar M 
(2014) The NiSi melting curve to $70 \mathrm{GPa}$. Phys Earth Planet Inter 233:13-23

Morard G, Andrault D, Guignot N, Siebert J, Garbarino G, Antonangeli D (2011) Melting of Fe-Ni-Si and Fe-Ni-S alloys at megabar pressures: implications for the core-mantle boundary temperature. Phys Chem Mineral 38:767-776

Ohnuma I, Abe S, Shimenouchi S, Omori T, Kainuma R, Ishida K (2012) Experimental and thermodynamic studies of the $\mathrm{Fe}-\mathrm{Si}$ binary system. ISIJ Int 52:540-548

Oka K, Hirose K, Tagawa S, Kidokoro Y, Nakajima Y, Kuwayama Y, Morard G, Coudurier N, Fiquet G (2019) Melting in the Fe-FeO system to $204 \mathrm{GPa}$ : implicaitons for oxygen in Earth's core. Am Mineral 104:1603-1607

Ozawa H, Hirose K, Tateno S, Sata N, Ohishi Y (2010) Phase transition boundary between $\mathrm{B} 1$ and $\mathrm{B} 8$ structures of $\mathrm{FeO}$ up to 210 GPa. Phys Earth Planet Inter 179:157-163

Ozawa H, Hirose K, Yonemitsu K, Ohishi Y (2016) High-pressure melting experiments on $\mathrm{Fe}-\mathrm{Si}$ alloys and implications for silicon as a light element in the core. Earth Planet Sci Lett 456:47-54

Redlich O, Kister AT (1948) Thermodynamics of nonelectrolyte solutions-X-Y-T relations in a binary system. Ind Eng Chem 40:341-345

Rubie DC, Frost DJ, Mann U, Asahara Y, Nimmo F, Tsuno K, Kegler P, Holzheid A, Palme H (2011) Heterogeneous accretion, composition and core-mantle differentiation of the Earth. Earth Planet Sci Lett 301:31-42

Saxena SK, Dubrovinsky LS (1998) Thermodynamics of iron phases at high pressures and temperatures. In: Manghnani MH, Yagi T (eds) Properties of earth and planetary materials. AGU, Washington, DC, pp 271-279
Saxena S, Eriksson G (2015) Thermodynamics of Fe-S at ultra-high pressure. Calphad 51:202-205

Siebert J, Badro J, Antonangeli D, Ryerson FJ (2013) Terrestrial accretion under oxidizing conditions. Science 339:1194-1197

Sinmyo R, Hirose K, Ohishi Y (2019) Melting curve of iron to 290 GPa determined in a resistance-heated diamond-anvil cell. Earth Planet Sci Lett 510:45-52

Tateno S, Kuwayama Y, Hirose K, Ohishi Y (2015) The structure of $\mathrm{Fe}-\mathrm{Si}$ alloy in Earth's inner core. Earth Planet Sci Lett 418:11-19

Tiwari GP (1978) Modification of Richard's rule and correlation between entropy of fusion and allotropic behaviour. Metal Sci 12:317-320. https://doi.org/10.1179/msc.1978.12.7

Tsuno K, Ohtani E, Terasaki H (2007) Immiscible two-liquid regions in the $\mathrm{Fe}-\mathrm{O}-\mathrm{S}$ system at high pressure: implications for planetary cores. Phys Earth Planet Inter 160:75-85

Wade J, Wood BJ (2005) Core formation and the oxidation state of the Earth. Earth Planet Sci Lett 236:78-95

Wagle F, Steinle-Neumann G (2019) Liquid iron equation of state to the terapascal regime from ab initio simulations. J Geophys Res. https://doi.org/10.1029/2018JB016994

Yamasaki M, Banno S (1972) Zoning pattern of extremely fractionated plagioclase crystallized from simple system. Bull (in Japanese with English abstract). Volcanol Soc Jpn 2:18-25

Publisher's Note Springer Nature remains neutral with regard to jurisdictional claims in published maps and institutional affiliations. 